\title{
FORMAÇÃO DE SUBPRODUTOS ORGÂNICOS HALOGENADOS NAS OPERAÇÕES DE PRÉ-OXIDAÇÃO COM CLORO, OZÔNIO E PEROXÔNIO E PÓS-CLORAÇÃO EM ÁGUA CONTÉNDO SUBTÂNCIA HÚMICA
}

\author{
FORMATION OF HALOGENATED ORGANIC BYPRODUCTS USING PREOXIDATION \\ WITH CHLORINE, OZONE AND PEROXONE AND POST-CHLORINATION OF \\ WATER CONTAINING HUMIC SUBSTANCES
}

\begin{abstract}
Cristina Filomena Pereira Rosa Paschoalato
Engenheira Química. Mestre e Doutora em Engenharia Civil área de concentração Hidráulica e Saneamento pela Escola de Engenharia de São Carlos da Universidade de São Paulo. Professora da Universidade de Ribeirão Preto (UNAERP)

\author{
MÁRCIO RESENDE TRIMAILOVAS
}

Aluno iniciação cientifica do Curso de Engenharia Química da UNAERP

LUIZ DI BERNARDO

Professor Titular do Departamento de Hidráulica e Saneamento da Escola de Engenharia de São Carlos - EESC/USP

Recebido: 27/09/06 Aceito: 22/07/08
\end{abstract}

\begin{abstract}
RESUMO
Dentre os compostos orgânicos halogenados que podem ser encontrados na água distribuída à população, destacam-se: trialometanos, ácidos haloacéticos, haloaldeídos, halocetonas, halofenóis e halopicrinas. O presente trabalho teve como objetivo avaliar o efeito da formação de 22 subprodutos com a utilização dos pré-oxidantes: cloro, ozônio e peroxônio. A formação de subprodutos foi observada em água preparada com adição de substâncias húmicas extraídas de solo turfoso, por meio do uso da pré-oxidação, presença e ausência de coagulação, filtração e pós-cloração. Os subprodutos foram quantificados por cromatografia gasosa com detetor de captura de elétrons. Os resultados obtidos mostraram que o uso de pré-oxidantes alternativos, ozônio e peroxônio, associados à coagulação, filtração e pós-cloração, formam quantidades pequenas de subprodutos.
\end{abstract}

PALAVRAS-CHAVES:Tratamento de água; substâncias húmicas; formação de subprodutos; compostos orgânicos halogenados, ozônio, peroxônio.

\begin{abstract}
When chlorine is used as preoxidant, the formation of halogenated organic byproducts found in water treated and distriduted to the population, are: trihalometane, haloacetic acids, haloaldehyde, haloketone, halophenol and halopicrin. This research was performed to evaluate the formation potential of 22 byproducts using the following preoxidants: chlorine, ozone and peroxone. The formation of byproducts was simulated in water prepared with the addition of humic substances extracted from peat soil by the use of preoxidants, coagulation, filtration, and postchlorination. Byproducts have quantified by gas chromatography with electron capture detector. The results obtained showed that the use of alternative preoxidants, such as ozone and peroxone, associated with coagulation, filtration, and post-chlorination form a low concentration of byproducts.
\end{abstract}

KEYWORDS:Treatment of drink water; humic substances; preoxidation; byproduct formation; halogenated compound, ozone, peroxone.

\section{INTRODUÇÃO}

A partir da década de 1970, diversos pesquisadores observaram que a matéria orgânica natural (MON) na água pode reagir com o cloro, causando a formação de compostos orgânicos halogenados. Segundo a Portaria $\mathrm{n}^{\circ} 518$ do Ministério da Saúde, em vigor desde 25 de março de 2004 , o valor máximo permissível de trialometanos é de $0,1 \mathrm{mg}$. $\mathrm{L}^{-1}$. Algumas alternativas têm sido propostas para evitar a formação desses subprodutos, destacando-se o uso de oxidantes e desinfetantes alternativos tais como ácido peracético, permanganato de potássio, peróxido de hidrogênio, dióxido de cloro, ozônio, monocloramina e radiação ultravioleta.
Este trabalho vem colaborar para sistematizar os ensaios a serem aplicados na etapa de pré-oxidação nas estaçōes de tratamento de água para avaliação do potencial de formaçãa de subprodutos.

Os possíveis subprodutos formados foram identificados e quantificados através de uma extração líquido-líquido e da técnica analítica por cromatografia 
gasosa com detetor de captura de elétrons (CG-DCE). Considerando a configuração do equipamento disponível no Laboratório de Recursos Hídricos da Universidade de Ribeirão Preto (UNAERP), foi possível quantificar 22 compostos orgânicos halogenados, sendo:

- Trialometanos (TAM): clorofórmio $\left(\mathrm{CHCl}_{3}\right)$; bromodiclorometano $\left(\mathrm{CHBrCl}_{2}\right)$; dibromoclorometano $\left(\mathrm{CHBr}{ }_{2} \mathrm{Cl}\right)$; bromofórmio $\left(\mathrm{CHBr}_{3}\right)$;

- Cloro hidrato $(\mathrm{CH})$ ou tricloro acetaldeído;

- Ácidos Haloacéticos (AHA): ácido monocloroacético (MCAA); ácido (DCAA) dicloroacético; ácido tricloroacético (TCAA); ácido monobromoacético (MCAA); ácido dibromoacético (DBAA); ácido tribromoacético (TBAA); ácido bromocloroacético (BCAA); ácido bromodicloroacético (BDCAA) e ácido dibromocloroacético (DBCAA);

- Haloacetonitrilas (HAN): dicloroacetonitrila (DCAN); tricloroacetonitrila (TCAN); dibromoacetonitrila (DBAN); tribromoacetonitrila (TBAN) e bromocloroacetonitrila (BCAN); (CP);

- Halopicrinas (HP): cloropicrina

- Haloacetonas (HC): 1,1-dicloropropanona (DCP) e 1,1,1-tricloropropanona (TCP).

\section{REVISÃO DA LITERATURA}

Os trialometanos aparecem principalmente na água potável, como subprodutos resultantes da reação entre substâncias químicas utilizadas no tratamento oxidativo com cloro livre e matéria orgânica, tais como os ácidos húmicos e fúlvicos, naturalmente presentes em mananciais de superfície utilizados para o abastecimento. Os fatores que podem influenciar a reação de formação de subprodutos são: tempo de contato; temperatura; $\mathrm{pH}$ do meio; características e concentração de matéria orgânica natural; dosagem de cloro aplicada; residual de cloro livre e concentração de brometo (Singer e Asce, 1994).

Os precursores de formação de TAM nos mananciais que são utilizados para o abastecimento podem variar sazonalmente e dependem do tipo de manancial (rios, lagos, reservatórios ou represas), tipo de solo, vegetação predominante, mata ciliar, ocupação urbana, industrial e agrícola (Pardo, 1996). Os ácidos húmicos e fúlvicos são as matérias orgânicas naturais encontradas em concentrações mais representativas, porém, outras formas de precursores podem eventualmente também estar presentes nas águas superficiais.

Segundo Muttamara et al (1995), o cloro pode formar TAM quando em contato com substâncias húmicas, que incluem ácidos húmicos, ácidos fúlvicos e ácido himatomelânico, com materiais de algas, principalmente a clorofila, sua biomassa, produtos extracelulares e com uma variedade de substâncias aromáticas presentes na água.

O uso de oxidante alternativo proporciona a eliminação ou a diminuição do uso de cloro na estação de tratamento de água (ETA). Vários oxidantes têm sido testados para redução da formação de subprodutos, destacando-se: cloraminas, dióxido de cloro, ozônio, permanganato de potássio, peróxido de hidrogênio e radiação ultravioleta.

Sens et al (2003), em pesquisa realizada para verificação da influência da pré-oxidação no tratamento de água por meio da filtração direta descendente, de mananciais com grandes concentraçôes de algas, efetuaram a pré-oxidação com ozônio e cloro. Os resultados indicaram o beneficio do uso de ozônio na préoxidação de água contendo altas concentrações de algas, obtendo redução na formação de TAM e produzindo água de melhor qualidade quando comparada à pré-oxidação com cloro.

$\mathrm{O}$ ozônio não tem sido muito utilizado no Brasil, mas tem sido empregado na Europa e nos EUA desde o final do século XIX, para desinfecção e oxidação de água de abastecimento público. É um dos oxidantes e desinfetantes mais efetivos usado em tratamento de água, necessita de menor tempo de contato, porém sua ação desinfetante se dá por meio do residual de oxigênio molecular remanescente, o qual é instável e raramente encontrado na água após alguns minutos do ozônio ter sido aplicado. O ozônio decompóe-se espontaneamente na água por meio de mecanismos complexos que envolvem a geração de radicais livres hidroxilas $(\cdot \mathrm{OH})$, os quais são muito reativos (Daniel et al, 2001).

Segundo USEPA (1999), o ozônio reage com a matéria orgânica natural da água e não forma subprodutos halogenados, mas resulta uma variedade de subprodutos orgânicos e inorgânicos.
Quando existe a presença do íon brometo na água a ser tratada, podem ser formados trialometanos (subprodutos bromados), aldeídos, ácidos (Singer e Asce, 1994). O uso do ozônio combinado com o peróxido de hidrogênio resulta no processo de oxidação denominado peroxônio, no qual há um acréscimo na concentração de $\cdot \mathrm{OH}$ em relação ao processo de ozonização.

As reaçōes do ozônio e do peroxônio com a matéria orgânica são competitivas. A principal diferença é que a ozonização depende do alto grau da oxidação direta da matéria orgânica pelo ozônio, enquanto o peroxônio depende principalmente da oxidação pelo radical hidroxila. (Daniel et al, 2001). A razão ótima em que se obtém a maior eficiência de oxidação é de 0,5 de $\mathrm{H}_{2} \mathrm{O}_{2}$ para 1 de $\mathrm{O}_{3}$.

Os resultados apresentados na literatura sobre a formação de subprodutos decorrentes da reação de matéria orgânica presente em mananciais, com diferentes pré-oxidantes, principalmente com cloro, revelam a importância da realização de estudos sobre a toxicidade destes subprodutos. No Brasil, tem sido investigada principalmente a formação de trialometanos na água potável, sendo os padrôes de potabilidade aqueles prescritos na Portaria 518/2004. Outros compostos, tais como os ácidos haloacéticos, cloro hidrato ou tricloro acetaldeído e haloacetonitrilas, que podem afetar igualmente a saúde da população, não são considerados na referida Portaria.

\section{MATERIAL E MÉTODOS}

A água de estudo foi preparada utilizando-se água subterrânea de um poço artesiano e extrato de substâncias húmicas (SHs), obtido a partir de solo turfoso por extração alcalina. Adicionou-se o extrato na água até obtenção de cor aparente de aproximadamente $200 \mathrm{uH}$. A água de estudo foi caracterizada conforme métodos da APHA et al (1998).

Os produtos químicos utilizados foram: hipoclorito de cálcio 65\% (em massa) na preparação da solução de cloro, solução de peróxido de hidrogênio $(30 \mathrm{~V})$ e um sistema piloto para geração de ozônio com uma coluna de acrílico com $1,5 \mathrm{~m}$ de altura e $11 \mathrm{~cm}$ de diâmetro.

Foram realizados ensaios para determinação da demanda de cloro. A 
temperatura da água foi mantida em $25 \pm 1{ }^{\circ} \mathrm{C}$, o tempo de contato na etapa da pré-oxidação foi de 30 minutos e a demanda foi calculada pela diferença entre a dosagem aplicada e o residual obtido. $\mathrm{O}$ método utilizado para determinação de cloro residual livre foi espectrofotométrico com DPD em espectrofotômetro visível da marca HACH, modelo DR 2000.

A capacidade de produção (geração) de ozônio na câmara de contato foi determinada pela adição de um volume de 11 litros de água de poço (sem SHs); adicionou-se uma massa de iodeto de potássio $(2 \% \mathrm{p} / \mathrm{v})$; a alimentação de oxigênio foi mantida com uma vazão de $2 \mathrm{~mL} / \mathrm{min}$ e o ozônio gerado foi conduzido e dissolvido na massa líquida de água da coluna por meio de uma mangueira com uma pedra porosa na extremidade; o excesso de gás de ozônio, denominado off gas, produzido e não dissolvido na câmara de contato foi adsorvido em um recipiente (erlenmeyer de $800 \mathrm{~mL}$ ) contendo um volume de $400 \mathrm{~mL}$ de uma solução de KI $2 \%$ p/v. Após a estabilidade do fluxo de oxigênio, foi ligado o aparelho para dar início à geração e introdução do ozônio na coluna e depois de um tempo de contato, interrompeu-se a geração de ozônio, imediatamente retirou-se o frasco do off gas e coletaram-se 3 alíquotas de $200 \mathrm{~mL}$ da fase líquida para determinação da concentração residual de ozônio. Esse procedimento foi repetido para os seguintes tempos de contato: $5,10,15,20,25$ e 30 min. As concentraçóes de residual de ozônio na fase líquida e na fase gasosa (off gas), foram determinadas por titrimetria pelo método iodométrico (APHA et al, 1998), diferenciando-se apenas nos volumes de amostra empregados na titulação.

As alíquotas coletadas foram fixadas com adição de $20 \mathrm{~mL}$ de solução de $\mathrm{H}_{2} \mathrm{SO}_{4}(1 \mathrm{~N})$ e protegidas contra a incidência de luz ambiente. Depois, as alíquotas foram tituladas com uma solução de tiossulfato de sódio $(0,025 \mathrm{~N})$ utilizando-se indicador de amido. $\mathrm{O}$ volume de solução de tiossulfato de sódio foi anotado.

Para o cálculo da produção de ozônio (em g/h), foram consideradas a soma da quantidade de ozônio dissolvido na fase líquida e a quantidade de ozônio adsorvida na fase gasosa (off gas) em função do tempo de contato, conforme Paschoalato (2005).
Após terem sido realizados os ensaios que permitiram o cálculo para a determinação da capacidade de geração de ozônio, foram realizados os ensaios de demanda utilizando-se um volume de $11 \mathrm{~L}$ de água de estudo introduzidos na coluna de ozonização. Os ensaios de demanda foram realizados para diferentes tempos de contato de aplicação de ozônio, sendo: 5, 10, 15, 20, 25, 30 e $40 \mathrm{~min}$.

Para cada tempo de contato foram determinadas as concentrações de residual de ozônio na fase líquida e na fase gasosa (off gas). Para a determinação da demanda de ozônio, foi necessário o cálculo da produção consumida considerando-se a capacidade de produção de ozônio subtraída do residual obtido na fase líquida e do residual da fase gasosa (off gas), conforme Paschoalato (2005).

A demanda de peroxônio foi definida pelos resultados obtidos em ensaios realizados com uso de diferentes proporçôes de peróxido de hidrogênio e ozônio. A proporção de aplicação de peróxido de hidrogênio/ozônio foi estudada com a realização de ensaios variando-se as razôes de $\mathrm{H}_{2} \mathrm{O}_{2} / \mathrm{O}_{3}: 0,5$; 1,0 e 2,0. A obtenção do menor valor de cor remanescente foi o parâmetro utilizado para a escolha da proporção $\mathrm{H}_{2} \mathrm{O}_{2} / \mathrm{O}_{3}$ adotada.

Posteriormente, foram realizados ensaios em jarteste para determinação da dosagem de sulfato de alumínio após a pré-oxidação. $\mathrm{O}$ parâmetro utilizado para determinação da dosagem apropriada de coagulante e do correspondente $\mathrm{pH}$ de coagulação, foi a obtenção de cor verdadeira remanescente máxima de $5 \mathrm{uH}$

Em seguida foram realizados os ensaios de pré-oxidação, coagulação e filtração (filtro de papel Whatman 40). Em 4 litros de água filtrada adicionou-se um tampão de fosfato para correção do $\mathrm{pH}$ em 7,0 e aplicou-se uma dosagem de cloro de $5,0 \mathrm{mg} / \mathrm{L}$ (pós-cloração). $\mathrm{O}$ frasco foi lacrado e armazenado em banho com temperatura mantida em $25^{\circ} \mathrm{C}$. Após os tempos de 0,5 e 24 horas, o frasco era aberto e recolheram-se alíquotas de $100 \mathrm{~mL}$, estas alíquotas foram transferidas para frascos contendo ácido ascórbico para descloração. As alíquotas de todos os frascos foram extraídas para determinação de compostos orgânicos halogenados. Uma amostra de água do poço sem adição de extrato de $\mathrm{SH}$ foi processada paralelamente, para controle e verificação de possíveis con- taminações. Os compostos orgânicos halogenados foram determinados por cromatografia gasosa com detector de captura de elétrons (CG-ECD), com base nos métodos da USEPA 551.1(1995) e 552 (1995). Os seguintes subprodutos foram investigados: (i) trialometanos: clorofórmio, bromodiclorometano, dibromoclorometano, bromofórmio; (ii) haloacetonitrilas: dicloroacetonitrila, tricloroacetonitrila, dibromoacetonitrila, tribromoacetonitrila, bromocloroacetonitrila; (iii) halopicrinas: cloropicrina; (iv) haloacetonas: 1,1-dicloropropanona, 1,1,1-tricloropropanona; (v) cloro hidrato; (vi) ácidos haloacéticos: monocloro ácido acético, monobromo ácido acético, dicloro ácido acético, tricloro ácido acético, bromocloro ácido acético, bromodicloro ácido acético, dibromo ácido acético, clorodibromo ácido acético, tribromo ácido acético.

Os ensaios para a determinação do potencial de formação de subprodutos orgânicos halogenados (PF) foram efetuados segundo adaptação da metodologia 5710 A e B (APHA et al, 1998). No ensaio final, realizado para cada pré-oxidante em estudo, mantiveram-se fixas as seguintes condiçôes: cor aparente da água de estudo, tempo de contato na pré-oxidação, dosagem de coagulante, tempo de mistura rápida, dosagem de cloro na pós-cloração, $\mathrm{pH}$ do meio, temperatura de incubação. Para cada pré-oxidante empregado, uma amostra da água de poço sem a presença de substâncias húmicas foi submetida às mesmas condições e foi denominada de "controle". Pelos resultados de subprodutos formados no tempo inicial $(0,5 \mathrm{~h})$ e final $(24 \mathrm{~h})$, foi possível efetuar o cálculo do potencial de formação após 24horas (PF 24h).

\section{RESULTADOS E DISCUSSÃO}

\section{Características da água de estudo}

Na Tabela 1 estão apresentados os principais resultados obtidos por análises físico-químicas da água do poço e da água de estudo.

\section{Resultados dos ensaios de demanda}

Com base nos ensaios realizados, observou-se que após 30 minutos 
Tabela I - Características físicas e químicas das águas utilizadas

\begin{tabular}{cccc}
\hline Parâmetro & Unidade & Água poço & Água de estudo \\
\hline $\mathrm{pH}$ & adimensional & 6,22 & 7,60 \\
Cor aparente & $\mathrm{uH}(\mathrm{PtCo})$ & 2 & 202 \\
Turbidez & $\mathrm{uT}$ & 0,21 & 2,5 \\
Carbono orgânico total & $\mathrm{mg} \mathrm{C/L}$ & $<1,00$ & 6,08 \\
UV 254nm & $\mathrm{cm}^{-1}$ & 0,013 & 0,264 \\
Alcalinidade de bicarbonatos & $\mathrm{mg} \mathrm{CaCO}_{3} / \mathrm{L}$ & 13 & 13 \\
Brometo & $\mathrm{mg} / \mathrm{L}$ & $<0,1$ & $<0,1$ \\
Sólidos totais & $\mathrm{mg} / \mathrm{L}$ & 17 & 65 \\
Ferro & $\mathrm{mg} \mathrm{Fe} / \mathrm{L}$ & $<0,001$ & 0,590 \\
\hline
\end{tabular}

de tempo de contato, a dosagem de $5 \mathrm{mg} \mathrm{Cl}_{2} / \mathrm{L}$ forneceu um residual de $2,78 \mathrm{mg} \mathrm{Cl}_{2} / \mathrm{L}$, obtendo-se uma demanda de cloro na pré-oxidação de aproximadamente $50 \%$ da dosagem. Considerando que a Portaria 518 cita como valor máximo permissível de cloro total a concentração de $5 \mathrm{mg} \mathrm{Cl}_{2} / \mathrm{L}$, adotou-se essa dosagem, que satisfaz as duas condições.

A capacidade de produção média obtida do ozônio foi de $0,19 \mathrm{gO}_{3} / \mathrm{h}$, Após tempo de contato de 30 minutos, a demanda e o residual de ozônio na fase liquida resultaram de aproximadamente 4,0 a $0,6 \mathrm{mg} \mathrm{O}_{3} / \mathrm{L}$ respectivamente. A cor aparente remanescente foi de $115 \mathrm{uH}$ e foi adotado aquele tempo de contato para a realização dos ensaios visando à determinação de subprodutos.

A demanda de peroxônio foi definida em função dos resultados obtidos nos ensaios preliminares realizados com diferentes dosagens e proporções de peróxido de hidrogênio e ozônio. Foram utilizadas as relações: $\mathrm{H}_{2} \mathrm{O}_{2} / \mathrm{O}_{3}$ de $0,5,1,0$, e 2,0. Com base nos resultados obtidos, adotou-se a proporção $\mathrm{H}_{2} \mathrm{O}_{2} / \mathrm{O}_{3}$ igual a 0,5 , sendo a dosagem de $\mathrm{H}_{2} \mathrm{O}_{2}$ fixada em 4,3mg $\mathrm{H}_{2} \mathrm{O}_{2} / \mathrm{L}$ e a de ozônio, em e $8,6 \mathrm{mg} \mathrm{O}_{3} / \mathrm{L}^{2}$ e tempo de contato de 30 minutos.

\section{Resultados dos ensaios de jarteste para determinação da dosagem de coagulante}

Estes ensaios foram efetuados separadamente para cada pré-oxidante estudado. $\mathrm{O}$ coagulante utilizado em todos os ensaios foi o sulfato de alumínio líquido, $\mathrm{Al}_{2}(\mathrm{SO} 4)_{3}$. 14,3 $\mathrm{H}_{2} \mathrm{O}$. A mistura rápida foi realizada com gradiente de velocidade $1000 \mathrm{~s}^{-1}$ e tempo de agitação de $1 \mathrm{~min}$, seguida de filtração em filtro de papel Whatman 40 e leitura de cor do filtrado. O resumo dos resultados obtidos para cada pré-oxidante estão apresentados na Tabela 2.

As condições estabelecidas para os ensaios com cloro foram: dosagem de cloro na pré-oxidação de $5 \mathrm{mg} / \mathrm{L} ; \mathrm{pH}$ da água de estudo igual a 7,60; adição de $100 \mu \mathrm{L} \mathrm{HCl}(1 \mathrm{~N})$ para obtenção de $\mathrm{pH}$ igual a 6,0 antes da coagulação, a dosagem de sulfato de alumínio (SA) de $14 \mathrm{mg} / \mathrm{L}$, com a qual a cor aparente do filtrado resultou menor que $5 \mathrm{uH}$.

Os resultados dos ensaios para as determinaçôes das dosagens de coagulante com a utilização de ozônio na pré-oxidação e para o tempo de contato de 30 minutos na pré-oxidação com ozônio, foram mais eficientes na remoção de cor (43\%) e a dosagem ótima de sulfato de alumínio foi de $20 \mathrm{mg} / \mathrm{L}$ com $\mathrm{pH}$ de coagulação igual a 5,63.

Os resultados dos ensaios para determinação da dosagem de coagulante com a utilização de peroxônio na pré-oxidação foram para dosagem de $18 \mathrm{mg} / \mathrm{L}$ de sulfato de alumínio, tendo a cor remanescente resultado abaixo de $5 \mathrm{uH}$ para a proporção $\mathrm{H}_{2} \mathrm{O}_{2} / \mathrm{O}_{3}$ de 0,5 .

\section{Subprodutos da pré- oxidação empregando- se cloro com e sem coagulação, seguida de filtração e pós-cloração}

$\mathrm{Na}$ Tabela 3 estão apresentados os valores obtidos dos subprodutos formados na pré-oxidação empregando-se cloro, com e sem coagulação, seguida de filtração e pós-cloração para os tempos de contato de 0,5 e 24 horas, além dos valores de controle e dos resultados do cálculo do potencial de formação de $24 \mathrm{~h}$, conforme metodologia recomendada pela AWWA, et al (1998).

Os valores de TAM resultaram abaixo do recomendado pela legislação. O maior valor obtido foi após $24 \mathrm{~h}$ com ausência de coagulação foi de $74,46 \mu \mathrm{g} / \mathrm{L}(72,06 \mu \mathrm{g} / \mathrm{L}$ de clorofórmio e $2,40 \mu \mathrm{g} / \mathrm{L}$ de bromodiclorometano). O cloro hidrato apresentou concen-

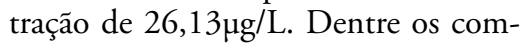
postos de haloacetonitrilas, ocorreu a formação de dicloroacetonitrila com $14,73 \mu \mathrm{g} / \mathrm{L}$; dentre as halocetonas, ocorreu a formação apenas do composto 1,1,1-tricloropropanona com valores variando de 2,42 a 3,83 $\mu \mathrm{g} / \mathrm{L}$. A cloropicrina não foi detectada dentro do limite de quantificação do método. A formação de ácidos haloacéticos foi superior à formação de TAM. Após $24 \mathrm{~h}$, o cloro hidrato apresentou concentração de $27,32 \mu \mathrm{g} / \mathrm{L}$.

Observou-se a formação de traços de subprodutos no controle, entretanto, tal fato pode ser relacionado à presença de outras fontes de carbono existentes na água do poço e às reaçōes com o coagulante.

Os valores de PF 24h, com o uso de coagulação, resultaram inferiores aos obtidos nos ensaios realizados sem a coagulação. Essa diferença mostrouse acentuada para TAM, tendo sido obtidos os seguintes valores de PF 24h:

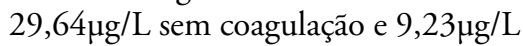
com coagulação. $\mathrm{O}$ cloro hidrato apresentou-se com PF $24 \mathrm{~h}$ de $6,56 \mu \mathrm{g} / \mathrm{L}$ sem


com coagulação. Os valores de PF $24 \mathrm{~h}$ para HAN resultaram de $6,32 \mu \mathrm{g} / \mathrm{L}$ sem coagulação e de $0,91 \mu \mathrm{g} / \mathrm{L}$ com coagulação. Em relação aos AHA, a redução devido à presença de coagulação não foi significativa, de $58,68 \mu \mathrm{g} / \mathrm{L}$ sem coagu- 
Tabela 2 - Resumo dos resultados obtidos nos ensaios de pré-oxidação

\begin{tabular}{cccc}
\hline Pré-oxidante & $\begin{array}{c}\text { Dosagem de sulfato de } \\
\text { alumínio }(\mathrm{mg} / \mathrm{L})\end{array}$ & $\begin{array}{c}\mathrm{pH} \text { de } \\
\text { coagulação }\end{array}$ & $\begin{array}{c}\text { Cor aparente } \\
\text { remanescente }(\mathrm{uH})\end{array}$ \\
\hline Cloro & 14 & 5,70 & 4 \\
Ozônio & 20 & 5,63 & 4 \\
Peroxônio & 18 & 5,61 & 3 \\
\hline
\end{tabular}

Tabela 3 - Subprodutos da pré-oxidação com cloro, coagulação, filtração em papel, pós-cloração, potencial de formação em $24 \mathrm{~h}$ a $25^{\circ} \mathrm{C}$

\begin{tabular}{|c|c|c|c|c|c|c|c|c|}
\hline \multirow{3}{*}{$\begin{array}{c}\text { Subprodutos } \\
(\mu \mathrm{g} / \mathrm{L})\end{array}$} & \multicolumn{8}{|c|}{ Tempos de contato $(\mathrm{h})$} \\
\hline & \multicolumn{2}{|c|}{ Controle } & \multicolumn{3}{|c|}{ Sem coagulação } & \multicolumn{3}{|c|}{ Com coagulação } \\
\hline & 0,5 & 24 & 0,5 & 24 & $\begin{array}{l}\mathrm{PF} \\
24 \mathrm{~h}\end{array}$ & 0,5 & 24 & $\begin{array}{l}\mathrm{PF} \\
24 \mathrm{~h}\end{array}$ \\
\hline \multicolumn{9}{|c|}{ Trialometanos: } \\
\hline Clorofórmio & 15,87 & 23,25 & 35,78 & 72,06 & 28,90 & 29,93 & 45,97 & 8,66 \\
\hline Bromodiclorometano & 0,87 & 1,41 & 1,12 & 2,40 & 0,74 & 1,24 & 2,35 & 0,57 \\
\hline Dibromoclorometano & $<0,1$ & $<0,1$ & $<0,1$ & $<0,1$ & $<0,1$ & $<0,1$ & $<0,1$ & $<0,1$ \\
\hline Bromofórmio & $<0,1$ & $<0,1$ & $<0,1$ & $<0,1$ & $<0,1$ & $<0,1$ & $<0,1$ & $<0,1$ \\
\hline Total TAM & 16,74 & 24,66 & 36,90 & 74,46 & 29,64 & 31,17 & 48,32 & 9,23 \\
\hline Cloro hidrato & 8,40 & 18,91 & 9,06 & 26,13 & 6,56 & 14,77 & 27,32 & 2,04 \\
\hline Cloropicrina & $<0,1$ & $<0,1$ & $<0,1$ & $<0,1$ & $<0,1$ & $<0,1$ & $<0,1$ & $<0,1$ \\
\hline \multicolumn{9}{|c|}{ Haloacetonitrilas: } \\
\hline Tricloroacetonitrila & $<0,1$ & $<0,1$ & $<0,1$ & $<0,1$ & $<0,1$ & $<0,1$ & $<0,1$ & $<0,1$ \\
\hline Dicloroacetonitrila & 1,70 & 4,40 & 5,71 & 14,73 & 6,32 & 3,60 & 7,21 & 0,91 \\
\hline Dibromoacetonitrila & $<0,1$ & $<0,1$ & $<0,1$ & $<0,1$ & $<0,1$ & $<0,1$ & $<0,1$ & $<0,1$ \\
\hline Bromocloroacetonitrila & $<0,1$ & $<0,1$ & $<0,1$ & $<0,1$ & $<0,1$ & $<0,1$ & $<0,1$ & $<0,1$ \\
\hline Total HAN & 1,70 & 4,40 & 5,71 & 14,73 & 6,32 & 3,60 & 7,21 & 0,91 \\
\hline \multicolumn{9}{|c|}{ Halocetonas: } \\
\hline 1,1,1-Tricloropropanona & 0,89 & 1,31 & 3,31 & 3,98 & 0,25 & 2,42 & 3,38 & 0,54 \\
\hline 1,1-Dicloropropanona & $<0,1$ & $<0,1$ & $<0,1$ & $<0,1$ & $<0,1$ & $<0,1$ & $<0,1$ & $<0,1$ \\
\hline Total HC & 0,89 & 1,31 & 3,31 & 3,98 & 0,25 & 2,42 & 3,38 & 0,54 \\
\hline \multicolumn{9}{|c|}{ Ácidos haloacéticos: } \\
\hline MCAA & 0,18 & 2,65 & 1,01 & 4,64 & 1,16 & 1,67 & 4,12 & $<0,1$ \\
\hline MBAA & 0,17 & 2,46 & 0,29 & 4,50 & 1,92 & 0,35 & 1,86 & $<0,1$ \\
\hline DCAA & 1,34 & 8,43 & 39,14 & 92,60 & 46,37 & 28,99 & 63,71 & 27,63 \\
\hline TCAA & 0,30 & 1,78 & 4,25 & 14,96 & 9,23 & 7,63 & 16,90 & 7,79 \\
\hline BCAA & 0,11 & 0,10 & $<0,1$ & $<0,1$ & $<0,1$ & $<0,1$ & $<0,1$ & $<0,1$ \\
\hline BDCAA & 0,01 & $<0,1$ & $<0,1$ & $<0,1$ & $<0,1$ & $<0,1$ & $<0,1$ & $<0,1$ \\
\hline DBAA & $<0,1$ & $<0,1$ & $<0,1$ & $<0,1$ & $<0,1$ & $<0,1$ & $<0,1$ & $<0,1$ \\
\hline CDBAA & $<0,1$ & $<0,1$ & $<0,1$ & $<0,1$ & $<0,1$ & $<0,1$ & $<0,1$ & $<0,1$ \\
\hline TBAA & $<0,1$ & $<0,1$ & $<0,1$ & $<0,1$ & $<0,1$ & $<0,1$ & $<0,1$ & $<0,1$ \\
\hline Total AHA & 2,09 & 15,42 & 44,69 & 116,70 & 58,68 & 38,64 & 86,59 & 34,62 \\
\hline
\end{tabular}


lação e de 34,62 $\mu \mathrm{g} / \mathrm{L}$ com coagulação. Nas Figuras 1 e 2 estão apresentados os resultados do potencial de formação de 24h, expressos em concentração $(\mathrm{Mg} / \mathrm{L})$ dos subprodutos formados em presença de cloro na pré-oxidação, com o emprego da coagulação, filtração em papel, pós-cloração e incubação a $25^{\circ} \mathrm{C}$ em função do tempo de contato.

\section{Subprodutos da pré-oxidação com ozônio, presença e ausência de coagulação, filtração e pós-cloração}

$\mathrm{Na}$ Tabela 4 estão apresentados os resultados de subprodutos formados com a dosagem aplicada de ozônio, filtração em papel, pós-cloração, incubação a $25^{\circ} \mathrm{C}$ e o cálculo do potencial de formação de $24 \mathrm{~h}$. Os AHA foram os subprodutos que mais se formaram, obtendo-se após $24 \mathrm{~h}, 127,29 \mu \mathrm{g} / \mathrm{L}$, se-

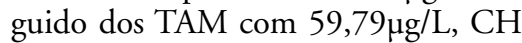
com $30,42 \mu \mathrm{g} / \mathrm{L}, \mathrm{HAN}$ com $11,64 \mu \mathrm{g} / \mathrm{L}$ e HC com $6,43 \mu \mathrm{g} / \mathrm{L}$. A cloropicrina foi identificada com valores próximos ao limite de detecção nas amostras de $6 \mathrm{~h}$ e $24 \mathrm{~h}$, sendo $0,15 \mu \mathrm{g} / \mathrm{L}$ e $0,25 \mu \mathrm{g} / \mathrm{L}$ respectivamente.

Os valores de TAM variaram de $36,87 \mu \mathrm{g} / \mathrm{L}$ a $54,76 \mu \mathrm{g} / \mathrm{L}$, para o $\mathrm{CH}$ os valores variaram de $10,99 \mu \mathrm{g} / \mathrm{L}$ a $25,8 \mu \mathrm{g} / \mathrm{L}$, para HAN os valores obtidos variaram de $5,11 \mu \mathrm{g} / \mathrm{L}$ a $15,33 \mu \mathrm{g} / \mathrm{L}$ e para $\mathrm{HK}$ variaram de $1,45 \mu \mathrm{g} / \mathrm{L}$ a $13,13 \mu \mathrm{g} / \mathrm{L}$. Nas amostras avaliadas não foi identificada a cloropicrina.

Nas Figuras 3 e 4, estão apresentados os resultados do potencial de formação de $24 \mathrm{~h}$ dos subprodutos expressos em concentração na pré-oxidação com ozônio, presença e ausência de coagulação, seguida de filtração e pós-cloração.

\section{Subprodutos da pré-oxidação com peroxônio presença e ausência de coagulação filtração em papel, pós-cloração}

$\mathrm{Na}$ Tabela 5 estão apresentados os resultados de subprodutos formados com o uso de peroxônio na pré-oxidação, presença e ausência de coagulação, filtração em papel, pós-cloração, incubação a $25^{\circ} \mathrm{C}$ e o cálculo do potencial de formação de $24 \mathrm{~h}$.

Após 24h, os valores de TAM e AHA ficaram próximos a $60 \mu \mathrm{g} / \mathrm{L}$ e os



Figura I - Potencial de formação de $24 h$, expressos em concentração $(\mu \mathrm{g} / \mathrm{L})$, dos subprodutos da pré-oxidação com cloro, filtração em papel, pós-cloração, incubação a $25^{\circ} \mathrm{C}$

demais subprodutos entre 10 e $30 \mu \mathrm{g} / \mathrm{L}$. Nas Figuras 5 e 6 estão apresentados os resultados de potencial de formação de $24 \mathrm{~h}$ dos subprodutos formados, com uso de peroxônio na pré-oxidação, ausência e presença de coagulação, filtração em papel e pós-cloração.

\section{Avaliação dos subprodutos formados em função dos pré-oxidantes}

Para uma melhor avaliação do potencial de formação dos subprodutos após $24 \mathrm{~h}$, estão apresentados os resultados de subprodutos em função dos pré-oxidantes aplicados. Os ensaios com ausência de coagulação formaram maior quantidade de TAM. O maior valor de PF $24 \mathrm{~h}$ de TAM ocorreu com o uso de cloro com

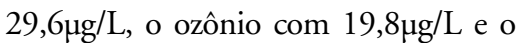
peroxônio com $25,2 \mu \mathrm{g} / \mathrm{L}$.

\section{Trialometanos}

Na Figura 7 estão apresentados os resultados de PF de $24 \mathrm{~h}$ de trialometanos em função dos pré-oxidantes aplicados na presença e ausência de coagulação. Em todos os ensaios os valores de TAM ficaram abaixo de $100 \mu \mathrm{g} / \mathrm{L}$.

\section{Cloro hidrato ou tricloro acetaldeído}

Na Figura 8 estão apresentados os resultados de PF de $24 \mathrm{~h}$ de cloro hidrato em função dos pré-oxidantes aplicados na presença e ausência de coagulação. No ensaio realizado com o uso do ozônio na pré-oxidação e na ausência de coagulação, obteve-se

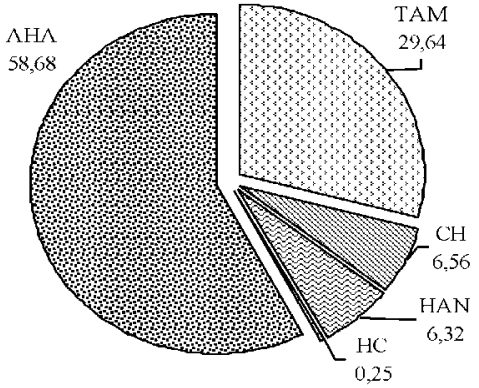

Figura 2 - Potencial de formação de 24h, expressos em concentração $(\mu \mathrm{g} / L)$, dos subprodutos da pré-oxidação com cloro, coagulação, filtração em papel, pós-cloração e incubação a $25^{\circ} \mathrm{C}$

o maior potencial formação de cloro hidrato, $23,1 \mu \mathrm{g} / \mathrm{L}$, seguido de $15,7 \mu \mathrm{g} / \mathrm{L}$ para o uso de peroxônio e $6,6 \mu \mathrm{g} / \mathrm{L}$ com o uso de cloro.

O menor PF 24h de CH, com coagulação, ocorreu nos ensaios com o uso de cloro com $2,0 \mu \mathrm{g} / \mathrm{L}$, e o máximo com ozônio com 16,6ug/L. Observou-se que para o pré-oxidante peroxônio, a presença ou ausência de coagulação resultou valores próximos de $\mathrm{PF} 24 \mathrm{~h}$ de $\mathrm{CH}$.

\section{Haloacetonitrila}

Na Figura 9 estão apresentados os resultados de PF de $24 \mathrm{~h}$ de haloacetonitrilas em função dos pré-oxidantes aplicados na presença e ausência de coagulação.

O maior valor obtido foi de $11,03 \mu \mathrm{g} / \mathrm{L}$ para o uso de ozônio na pré-oxidação e na presença de coagulação. Para o cloro e o peroxônio o uso de coagulante resultou em menor formação.

\section{Halocetonas}

Na Figura 10 estão apresentados os resultados de PF de $24 \mathrm{~h}$ de halocetonas em função dos pré-oxidantes aplicados, na presença e ausência de coagulação.

O maior valor de PF $24 \mathrm{~h}$ de $\mathrm{HC}$ foi obtido no ensaio com uso de préoxidação com peroxônio em presença de coagulação, seguido do ozônio com $13,2 \mu \mathrm{g} / \mathrm{L}$ e cloro com $0,5 \mu \mathrm{g} / \mathrm{L}$. Nos ensaios realizados em ausência de coagulação, o maior PF $24 \mathrm{~h}$ de $\mathrm{HC}$ foi de peroxônio, com $11,3 \mu \mathrm{g} / \mathrm{L}$, seguido de ozônio com $6,6 \mu \mathrm{g} / \mathrm{L}$. 
Tabela 4- Subprodutos da pré-oxidação com ozônio, filtração, coagulação e incubação por $24 \mathrm{~h}$ a $25^{\circ} \mathrm{C}$ e PF de $24 \mathrm{~h}$

\begin{tabular}{|c|c|c|c|c|c|c|c|c|}
\hline \multirow{3}{*}{$\begin{array}{l}\text { Subprodutos } \\
(\mu \mathrm{g} / \mathrm{L})\end{array}$} & \multicolumn{8}{|c|}{ Tempos de contato $(\mathrm{h})$} \\
\hline & \multicolumn{2}{|c|}{ Controle } & \multicolumn{3}{|c|}{ Sem coagulação } & \multicolumn{3}{|c|}{ Com coagulação } \\
\hline & 0,5 & 24 & 0,5 & 24 & $\begin{array}{l}\mathrm{PF} \\
24 \mathrm{~h} \\
\end{array}$ & 0,5 & 24 & $\begin{array}{l}\mathrm{PF} \\
24 \mathrm{~h} \\
\end{array}$ \\
\hline \multicolumn{9}{|c|}{ Trialometanos: } \\
\hline Clorofórmio & 25,24 & 26,49 & 36,13 & 55,10 & 20,22 & 32,68 & 47,84 & 16,41 \\
\hline Bromodiclorometano & 4,29 & 3,95 & 4,25 & 4,69 & 0,10 & 4,19 & 6,92 & 2,39 \\
\hline Dibromoclorometano & $<0,1$ & $<0,1$ & 0,54 & $<0,1$ & $<0,1$ & $<0,1$ & $<0,1$ & $<0,1$ \\
\hline Bromofórmio & $<0,1$ & $<0,1$ & $<0,1$ & $<0,1$ & $<0,1$ & $<0,1$ & $<0,1$ & $<0,1$ \\
\hline Total TAM & 29,53 & 30,44 & 40,92 & 59,79 & 19,78 & 36,87 & 54,76 & 16,98 \\
\hline Cloro hidrato & 3,59 & 1,81 & 9,07 & 30,42 & 23,13 & 10,99 & 25,82 & 16,61 \\
\hline Cloropicrina & 0,83 & 0,37 & $<0,1$ & 0,25 & $<0,1$ & $<0,1$ & $<0,1$ & 0,46 \\
\hline \multicolumn{9}{|c|}{ Haloacetonitrilas: } \\
\hline Tricloroacetonitrila & $<0,1$ & $<0,1$ & $<0,1$ & $<0,1$ & $<0,1$ & $<0,1$ & $<0,1$ & $<0,1$ \\
\hline Dicloroacetonitrila & 1,46 & 0,57 & 1,35 & 5,90 & 5,44 & 1,55 & 9,55 & 8,89 \\
\hline Dibromoacetonitrila & $<0,1$ & $<0,1$ & $<0,1$ & $<0,1$ & $<0,1$ & $<0,1$ & $<0,1$ & $<0,1$ \\
\hline Bromocloroacetonitrila & 1,06 & 1,14 & 2,86 & 5,74 & 2,80 & 3,56 & 5,78 & 2,14 \\
\hline Total HAN & 2,52 & 1,71 & 4,21 & 11,64 & 8,24 & 5,11 & 15,33 & 11,03 \\
\hline \multicolumn{9}{|c|}{ Halocetonas: } \\
\hline 1,1,1-Tricloropropanona & $<0,1$ & $<0,1$ & $<0,1$ & 5,43 & 5,43 & $<0,1$ & 11,96 & 11,96 \\
\hline 1,1-Dicloropropanona & 3,09 & 1,54 & 1,39 & 1,00 & $<0,1$ & 1,45 & 1,17 & 1,27 \\
\hline Total HC & 3,09 & 1,54 & 1,39 & 6,43 & 6,59 & 1,45 & 13,13 & 13,23 \\
\hline \multicolumn{9}{|c|}{ Ácidos haloacéticos: } \\
\hline MCAA & $<0,1$ & 14,85 & 9,89 & 33,93 & 9,19 & 6,36 & 102,50 & 80,55 \\
\hline MBAA & $<0,1$ & 2,21 & 1,66 & 2,13 & $<0,1$ & $<0,1$ & 5,24 & $<0,1$ \\
\hline DCAA & $<0,1$ & 6,44 & 44,23 & 71,77 & 21,10 & 17,66 & 68,61 & 33,21 \\
\hline TCAA & 4,42 & 1,75 & 5,95 & 17,43 & 14,15 & 0,81 & 9,74 & 12,41 \\
\hline BCAA & 1,55 & 2,98 & 1,32 & 2,03 & $<0,1$ & 5,89 & 14,21 & 0,98 \\
\hline BDCAA & 1,11 & $<0,1$ & $<0,1$ & $<0,1$ & 1,11 & $<0,1$ & $<0,1$ & 1,11 \\
\hline DBAA & $<0,1$ & 0,47 & $<0,1$ & $<0,1$ & $<0,1$ & $<0,1$ & $<0,1$ & $<0,1$ \\
\hline CDBAA & $<0,1$ & $<0,1$ & $<0,1$ & $<0,1$ & $<0,1$ & 9,68 & $<0,1$ & $<0,1$ \\
\hline TBAA & $<0,1$ & $<0,1$ & $<0,1$ & $<0,1$ & $<0,1$ & $<0,1$ & $<0,1$ & $<0,1$ \\
\hline Total AHA & 7,08 & 28,70 & 63,05 & 127,29 & 42,62 & 40,40 & 200,30 & 138,28 \\
\hline
\end{tabular}

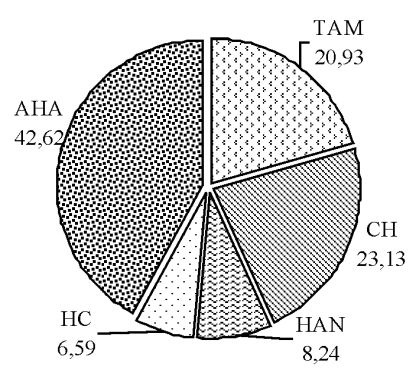

Figura 3 - Potencial de formação após 24 h de tempo de contato para pré-oxidação com ozônio, filtração em papel, pós-cloração e incubação a $25^{\circ} \mathrm{C}$, expressos em concentração $(\mu \mathrm{g} / \mathrm{L})$

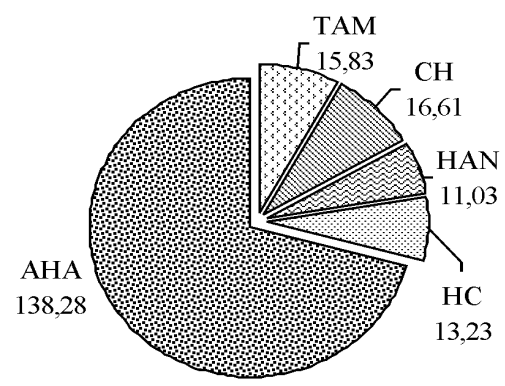

Figura 4 - Potencial de formação após 24 h de tempo de contato para pré-oxidação com ozônio, coagulação, filtração em papel, pós-cloração, incubação a $25^{\circ} \mathrm{C}$, expressos em concentração $(\mu \mathrm{g} / \mathrm{L})$ 
Paschoalato, C. F. P. R.; Trimailovas, M. R.; Di Bernardo, L.

Tabela 5 - Subprodutos da pré-oxidação com peroxônio, com presença e ausência de coagulação, filtração, em papel, pós-cloração, incubação por $24 \mathrm{~h}$ a $25^{\circ} \mathrm{C}$ e PF $24 \mathrm{~h}$

\begin{tabular}{|c|c|c|c|c|c|c|c|c|}
\hline \multirow{3}{*}{$\begin{array}{l}\text { Subprodutos } \\
(\mu \mathrm{g} / \mathrm{L})\end{array}$} & \multicolumn{8}{|c|}{ Tempos de contato (h) } \\
\hline & \multicolumn{2}{|c|}{ Controle } & \multicolumn{3}{|c|}{ Sem coagulação } & \multicolumn{3}{|c|}{ Com coagulação } \\
\hline & 0,5 & 24 & 0,5 & 24 & PF 24h & 0,5 & 24 & PF 24h \\
\hline \multicolumn{9}{|c|}{ Trialometanos: } \\
\hline Clorofórmio & 20,89 & 23,80 & 24,44 & 53,83 & 26,48 & 25,85 & 39,45 & 10,69 \\
\hline Bromodiclorometano & $<0,1$ & 2,23 & 2,11 & 3,01 & $<0,1$ & 2,35 & 3,30 & $<0,1$ \\
\hline Dibromoclorometano & $<0,1$ & $<0,1$ & $<0,1$ & $<0,1$ & $<0,1$ & $<0,1$ & $<0,1$ & 0,00 \\
\hline Bromofórmio & $<0,1$ & $<0,1$ & $<0,1$ & $<0,1$ & $<0,1$ & $<0,1$ & $<0,1$ & 0,00 \\
\hline Total TAM & 20,89 & 26,03 & 26,55 & 56,84 & 25,15 & 28,20 & 42,75 & 9,41 \\
\hline Cloro hidrato & $<0,1$ & 7,26 & 6,09 & 29,04 & 15,69 & 10,73 & 31,00 & 13,01 \\
\hline Cloropicrina & $<0,1$ & 1,06 & 0,44 & $<0,1$ & 0,44 & $<0,1$ & 1,22 & 0,16 \\
\hline \multicolumn{9}{|c|}{ Haloacetonitrilas: } \\
\hline Tricloroacetonitrila & $<0,1$ & $<0,1$ & $<0,1$ & $<0,1$ & $<0,1$ & $<0,1$ & $<0,1$ & $<0,1$ \\
\hline Dicloroacetonitrila & $<0,1$ & 2,69 & 1,44 & 5,54 & 1,41 & 1,88 & 4,39 & $<0,1$ \\
\hline Dibromoacetonitrila & $<0,1$ & $<0,1$ & $<0,1$ & $<0,1$ & $<0,1$ & $<0,1$ & $<0,1$ & $<0,1$ \\
\hline Bromocloroacetonitrila & $<0,1$ & 1,54 & 2,63 & 6,88 & 2,71 & 3,46 & 6,73 & 1,73 \\
\hline Total HAN & $<0,1$ & 4,23 & 4,07 & 12,42 & 4,12 & 5,34 & 11,12 & 1,55 \\
\hline \multicolumn{9}{|c|}{ Halocetonas: } \\
\hline $1,1,1$-Tricloropropanona & $<0,1$ & $<0,1$ & $<0,1$ & 11,32 & 11,32 & $<0,1$ & 14,77 & 14,77 \\
\hline 1,1-Dicloropropanona & $<0,1$ & $<0,1$ & $<0,1$ & $<0,1$ & $<0,1$ & $<0,1$ & $<0,1$ & $<0,1$ \\
\hline Total HC & $<0,1$ & $<0,1$ & $<0,1$ & 11,32 & 11,32 & $<0,1$ & 14,77 & 14,77 \\
\hline \multicolumn{9}{|c|}{ Ácidos haloacéticos: } \\
\hline MCAA & 4,46 & 21,06 & 6,43 & 21,65 & $<0,1$ & 4,48 & 24,76 & 3,68 \\
\hline MBAA & $<0,1$ & 1,04 & 0,80 & 3,35 & 1,51 & 0,40 & 1,53 & $<0,1$ \\
\hline DCAA & 1,48 & 4,16 & 7,69 & 21,12 & 10,75 & 2,70 & 13,16 & 7,78 \\
\hline TCAA & 0,60 & 1,51 & 2,64 & 9,39 & 5,84 & 3,47 & 9,56 & 5,18 \\
\hline BCAA & $<0,1$ & $<0,1$ & $<0,1$ & $<0,1$ & $<0,1$ & $<0,1$ & $<0,1$ & $<0,1$ \\
\hline BDCAA & 0,58 & $<0,1$ & $<0,1$ & $<0,1$ & 0,58 & $<0,1$ & $<0,1$ & 0,58 \\
\hline DBAA & $<0,1$ & 0,19 & 0,13 & 0,90 & 0,58 & 0,29 & 0,48 & $<0,1$ \\
\hline CDBAA & $<0,1$ & $<0,1$ & $<0,1$ & $<0,1$ & $<0,1$ & $<0,1$ & $<0,1$ & $<0,1$ \\
\hline TBAA & $<0,1$ & $<0,1$ & $<0,1$ & $<0,1$ & $<0,1$ & $<0,1$ & $<0,1$ & $<0,1$ \\
\hline Total AHA & 7,12 & 27,96 & 17,69 & 56,41 & 17,88 & 11,34 & 49,49 & 17,31 \\
\hline
\end{tabular}

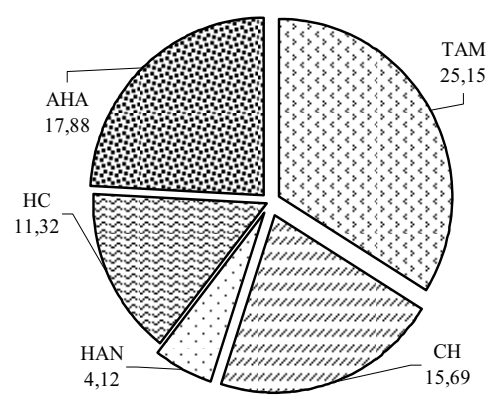

Figura 5 - Valores de potencial de formação após 24h de tempo de contato para pré-oxidação com peroxônio, filtração em papel, pós-cloração, incubação a $25^{\circ} \mathrm{C}$, expressos em concentração ( $\left.\mu \mathrm{g} / \mathrm{L}\right)$

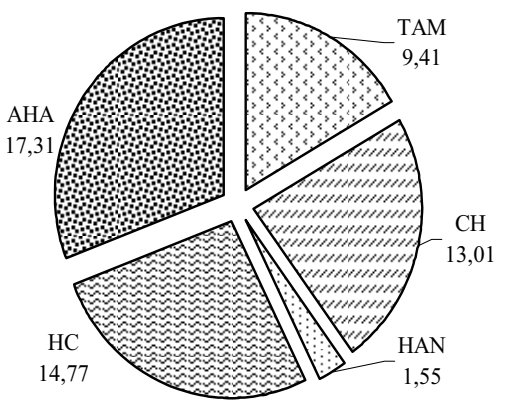

Figura 6 - Valores de potencial de formação após $24 h$ de tempo de contato para pré-oxidação com peroxônio, coagulação, filtração em papel, pós-cloração, incubação a $25^{\circ} \mathrm{C}$, expressos em concentração $(\mu \mathrm{g} / \mathrm{L})$. 


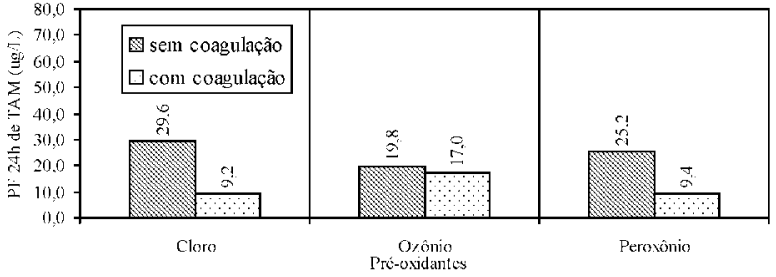

Figura 7 - Potencial de formação de 24h de trialometanos em presença e ausência de coagulação, filtração em papel, pós-cloração, incubação a $25^{\circ} \mathrm{C}$ em função dos pré-oxidantes aplicados



Figura 8 - Potencial de formação de 24 h de cloro hidrato em presença e ausência de coagulação, filtração em papel, pós-cloração, incubação a $25^{\circ} \mathrm{C}$ em função dos pré-oxidantes aplicados

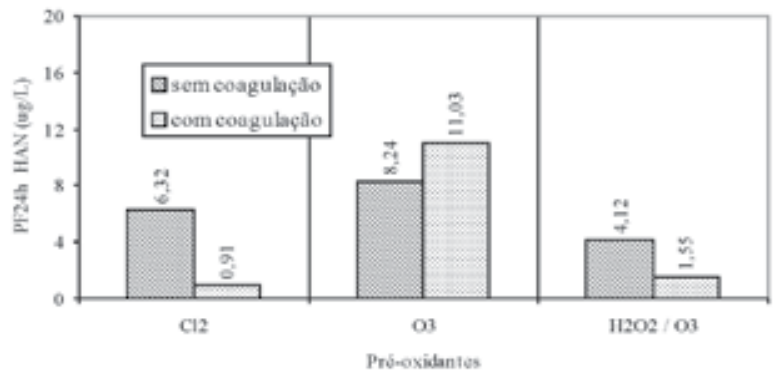

Figura 9 - Potencial de formação de 24 h de haloacetonitrilas em presença e ausência de coagulação, filtração em papel, pós-cloração, incubação $a 5^{\circ} \mathrm{C}$ em função dos pré-oxidantes aplicados

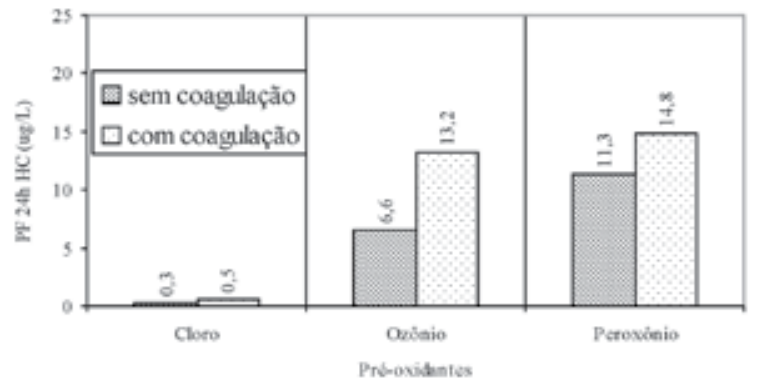

Figura 10 - Potencial de formação de $24 \mathrm{~h}$ de halocetonas em presença e ausência de coagulação, filtração em papel, pós-cloração, incubação a $25^{\circ} \mathrm{C}$ em função dos pré-oxidantes aplicados

\section{Ácidos haloacéticos}

$\mathrm{Na}$ Figura 11 estão apresentados os resultados de PF de $24 \mathrm{~h}$ de ácidos haloacéticos em função dos pré-oxidantes aplicados na presença e ausência de coagulação. $\mathrm{O}$ maior valor obtido de PF $24 \mathrm{~h}$ de AHA foi de $138,3 \mu \mathrm{g} / \mathrm{L}$ no ensaio com o uso de ozônio na préoxidação e na presença de coagulação. $\mathrm{Na}$ ausência de coagulação, o maior valor obtido foi com uso de cloro com $58,7 \mu \mathrm{g} / \mathrm{L}$.

A presença e a ausência de coagulação não resultaram alterações significativas quando os pré-oxidantes utilizados foram: cloro, peróxido de hidrogênio e peroxônio.

\section{Cloropicrinas}

Nas condições em que os ensaios experimentais foram realizados, as cloropicrinas não foram formadas ou ficaram abaixo do limite de quantificação do método analítico empregado $(<0,1 \mu \mathrm{g} / \mathrm{L})$.

\section{CONCLUSÕES E RECOMENDAÇỐES}

Com base no trabalho realizado, concluiu-se que:

a. A formação de ácidos haloacéticos é superior à formação de trialometanos, cloro hidrato, haloacetonitrilas e halocetonas;

b. A coagulação com sulfato de alumínio proporcionou redução na formação de trialometanos, cloro hidratoe haloacetonitrilas para os pré-oxidantes estudados;

c. A pré-oxidação com ozônio reduziu a formação de subprodutos, exceto a de AHA, porém, o ozônio foi o pré-oxidante que apresentou menor potencial de formação de trialometanos em 24 horas, sem a etapa da coagulação;

d. O uso do peroxônio mostrouse uma alternativa interessante, tendo sido obtido o potencial de formação de $25 \mu \mathrm{g} / \mathrm{L}$ de trialometanos.

e. Houve a formação de cloro hidrato em todos os ensaios realizados com os pré-oxidantes estudados.

Em função dos resultados obtidos nesta investigação, recomenda-se: a) realização de ensaios com pré-oxidantes alternativos para água contendo substancias húmicas de origem aquática; b) que o Ministério da saúde 




Figura I I-Potencial de formação de 24 h de ácidos haloacéticos em presença e ausência de coagulação, filtração em papel, pós-cloração, incubação a $25^{\circ} \mathrm{em}$ função dos pré-oxidantes aplicados

estabeleça uma regulamentação incluindo ácidos haloacéticos e cloro hidrato nos padrôes de qualidade de água para consumo humano.

\section{AGRADECIMENTOS}

Os autores agradecem à FAPESP pelos recursos obtidos para a execução deste trabalho, a EESC-USP e UNAERP pelo uso de instalaçôes e equipamentos de laboratório.

\section{REFERÊNCIAS}

APHA, AWWA, WPCF. Standard Methods for the Examination of Water and Wastewater. $19^{\text {th }}$ edition, Washington, USA. 1998.

AWWA. Water Quality \& Treatment Handbook of Comnunity Wats Suplies. Fifth edition, Cap.12, p.12,3. 1999.

BRASIL. Leis Decretos, etc. Ministério da Saúde. Portaria 518/GM. Brasília, Brasil. 25 de março de 2004.

DANIEL, L.A. et al. Processos de desinfecção e desinfetantes alternativos na produção de água potável. cap. 2. ABES-PROSAB. Rio de Janeiro, RJ. 2001.
MUTTAMARA, S.; SALES, C. I. GAZALI, Z The formation of thihalomethanos from chemical disinfectantes and humic substances in drinking water. Water Supply, v.13, n.2. p 105-17. 1995.

PARDO, S.D.A. Avaliação do potencial de formação de trihalometanos em sistemas de abastecimento de água. Dissertação de mestrado, 119p. Faculdade de Engenharia Civil, Universidade Estadual de Campinas. 1996.

PASCHOALATO, C.F.P.R. Efeito da pré-oxidação, coagulação, filtração e pós-cloração na formação de subprodutos orgânicos halogenados em águas contendo substâncias húmicas. Tese de doutorado, 154p. Escola de Engenharia de São Carlos, Universidade de São Paulo. 2005.

SENS, L. M. et al. Influência da pré-oxidação na tratabilidade das águas através da filtração direta descendente em mananciais com grandes concentraçôes de algas. In: $22^{\circ}$ CONGRESSO BRASILEIRO DE ENGENHARIA SANITÁRIA E AMBIENTAL. ABES - CD-ROM, I-094, Joinville, Santa Catarina. set. 2003.

SINGER, P. C.; ASCE, M. Control of disinfection by-products in drinking water. JEE-ASCE, v. 120, n. 4., p.727-741. July/August, USA. 1994.

USEPA- UNITED STATES ENVIRONMENTAL PROTECTION AGENCY. Trihalometanes in drinking water: Sampling, Analysis, Monitoring, and Compilance. EPA 570/9-83-002, august. 2002.
USEPA- UNITED STATES ENVIRONMENTAL PROTECTION AGENCY. Alternative Disinfectants and Oxidants Guindance Manual. Washington, EPA 5-1april. 1999.

USEPA- UNITED STATES ENVIRONMENTAL PROTECTION AGENCY. Method 551.1. Determination of chlorination disinfection byproducts, chlorinated solvents, and halogenated pesticides/herbicides in drinking water by liquid-liquid extracion and gas chromatografhy with electron-capture detection. CD-ROM Revisão 1. Set.1995, Ohio, USA. 1995.

USEPA- UNITED STATES ENVIRONMENTAL PROTECTION AGENCY. Method 552. Determination of haloacetic acids and dalapon in, in drinking water by liquid-liquid extracion, derivatization and gas chromatografhy with electron-capture detection. CD-ROON Revisão 1. Set.1995, Ohio, USA. 1995.

\section{Endereço para correspondência:}

Luiz Di Bernardo

Departamento de Hidráulica

e Saneamento da Escola de

Engenharia de São Carlos - EESCI

USP - Universidade de São Paulo Av.

Trabalhador São-carlense, 400

13566-590 São Carlos - SP - Brasil

Tel.: (I6) 3273-9528

Fax: (I6) 3273-8263

E-mail: bernardo@sc.usp.br 